\title{
The emergence of complexity and novelty in the human fossil record
}

Rebecca Rogers Ackermann ${ }^{1,2}$ and Lauren Schroeder ${ }^{2,3}$

1. Department of Archaeology, University of Cape Town

2. Human Evolution Research Institute, University of Cape Town

3. Department of Anthropology, University of Toronto Mississanga

[In: Humility, Wisdom and Grace in Deep Time: A Conversation between Theology and Evolutionary Anthropology. Editors.: Agustin Fuentes and Celia Deane-Drummond. Oxford Press, scheduled for publication in 2019]

\begin{abstract}
$\underline{\text { Abstract }}$
Outside of possible evidence for more complex social practices (e.g. longevity post-trauma, preserved infant remains), the fossil record of human evolution is limited in its ability to address the transition towards transcendental forms of wisdom. Indeed, it is difficult to equate our modern intellectual condition with deep past biological indicators at all. Nonetheless, arguably the best and most visible evidence for biological changes that might be precursors to these abilities are in the form of increasing complexity and/or novelty. We see these patterns in the hominin fossil record most strongly at the emergence and diversification of our genus, and in the Middle to Late Pleistocene record with the emergence of our species. Here we will first give a brief overview of the human fossil record, and will then focus on these two time periods, and the question of what produces such complexity/novelty.
\end{abstract}

